\title{
Interactive comment on "Using an integrated hydrological model to estimate the usefulness of meteorological drought indices in a changing climate" by Diane von Gunten et al.
}

\section{Anonymous Referee \#2}

Received and published: 31 March 2016

\section{General Comments:}

This study compares and contrast the reliability of seven meteorological drought indices to assess/predict the hydrological impacts of draughts for current and future climate in a semi-arid catchment in Spain. Not only climate scenarios projected by GCMs but also different irrigation scenarios are considered to evaluate these impacts. They compare drought indices produced based on GCMs with simulated hydrologic variables including discharge, groundwater levels and water deficit. At the bottom line, this study shows why do we need a hydrological model to study the hydrological impacts of future droughts. In case of unavailability of hydrological model, several drought indices should be used to our analyses, especially which take both precipitation and potential 
evapotranspiration (PET). Again, future climate predictions not only result in changes in precipitation but also in PET. Hence inclusion of both variables in the drought index inhibits overestimation/underestimation of draught impacts.

I believe that the paper will be a good contribution to the Hydrology and Earth System Sciences. My major concern about the length of the Methods Section.

The paper is well written, clear, easy to follow and well structured. I enjoyed reading when all details are given clearly in the Methods Section. However, giving details ended up with a long Methods Sections. As seen, the Methods Section (Section 2) consists of 9 pages of the 19-page paper. Hence, one of the recommendation is moving the whole sub-parts of "Drought Indices (2.6.X)" the Appendix. Hence, if the reader wants to freshen his/her memory about these indices, then consult this Appendix. This moving will cause a two-page reduction in Methods Section.

I am not a strong proponent of any other recommendation on this part. These are my recommendations, the authors may (or not) follow these: - The formula of the PenmanMonteith equation may be given in the Appendix. - I am not sure how much do we need the details of the Person's correlation coefficient. If the authors want to give it, it may be given in the Appendix.

Finally, I do believe that some of these recommendations will shorten the Methods Section.

\section{Minor Point:}

I was curious about the current irrigation usage, and noticed that the irrigation usage is enormous. The irrigation from the Aragon River collected at the Yesa reservoir in 2011 is $2.1 .106 \mathrm{~m} 3$. Size of the irrigated portion is $3.54 \mathrm{~km} 2$ from von Gunten et al. (2015). Hence the irrigation depth is $593 \mathrm{~mm}$. On top of this number, mean annual precipitation (MAP) is $\sim 400 \mathrm{~mm}$. The runoff, from Figure 6, with $0 \mathrm{SPEI}, 2-3 \mathrm{~m} 3 / \mathrm{s}$ which is equivalent to $23-35 \mathrm{~mm}$ for the entire basin. If I assume no deep drainage from 
irrigation, water usage is roughly $1,000 \mathrm{~mm}$ per year. This number intrigued me in a lot. First, is this irrigation sustainable over the long-term period? $\sim 600 \mathrm{~mm}$ of irrigation within a $400 \mathrm{~mm}$ of MAP environment makes the farmers, ecosystem very dependent on this irrigation, or headwater sources, the Pyrenees. Secondly, this value seems somewhat upper limit for maximum irrigation. Because the ecosystem is approaching towards the PET which is $1300 \mathrm{~mm}$. Another saying from water-limited to energylimited.

I am not sure whether or not the authors agree with me, but I definitely encourage the authors write a few sentences into the Conclusion or the Discussion part about the sustainability of this current land-cover transformation. The demand for water due to PET changes of future climate (as seen drier outcomes of ETHZ) is much less significant than those of current land-cover transformation.

Minor Comments:

P4. L5. Wording. I recommend forcing only for meteorology. ....changes in meteorological forcing and land-use cover.

P8. L17. Please cite "Table 1" before citing "Table 2". It may be good to cite "Table 1" in Section 2.1. Or you may reorder Tables.

P19. L10. Please change .... project 'is' to ... project 'are'. Data may use as a singular or plural, however in two previous sentences you used as plural, hence to ensure consistency. Figure 6. Can you ensure the y-scale similar for both figures? I think the limits are [0 0.08] or [0 0.07]. And definitely, y-value (discharge) must be truncate at zero. Morevoer, it needs a better colour selection.

Interactive comment on Hydrol. Earth Syst. Sci. Discuss., doi:10.5194/hess-2015-510, 2016.

Printer-friendly version

Discussion paper 